\title{
Intervenções
} \section{assistidas por animais: considerações gerais}

\section{Animal-assisted interventions: general considerations}

\section{Resumo}

O objetivo desta pesquisa é verificar na literatura se a aplicação das intervenções assistidas por animais (IAA) pode ser benéfica para os envolvidos. Foi constatado que os estudos ainda são incipientes, mas que a área vem crescendo significativamente e observações mais robustas estão sendo publicadas. Nos materiais consultados, há fortes indícios de que as IAA geram inúmeros benefícios em diversos cenários, de crianças até idosos, sem distinção de público. Este ensaio teórico se caracteriza por uma revisão da literatura. Critérios de inclusão e exclusão, bem como descritores, foram definidos e utilizados para assegurar o conteúdo dos materiais consultados. Por fim, é sugerida a realização de estudos com critérios metodológicos mais rigorosos, com amostras maiores, utilizando grupos de controle, e que sejam aplicados por um período mais longo.

\section{Abstract}

The aim of this research is to verify in the literature if the application of animal-assisted interventions (AAI) can be beneficial to those involved. It was verified that these studies are still incipient, but that the area has been growing significantly and more robust studies are being published. There is strong evidence on consulted materials on AAI benefits in the most diverse scenarios, from children to the elderly, without any group distinction. This theoretical essay is characterized by a literature revision. Inclusion and exclusion criteria, as well as their descriptors, have been defined and used to ensure the content of the consulted materials. Finally, it is proposed that new studies with more stringent methodological criteria, larger samples, control groups, and longer periods must be performed. 
Aline Fernanda Squilasse ${ }^{1}$ Fernando Tadeu Squilasse Junior ${ }^{2}$
Rua Antônio Celeguini, 427, Jardim Almeida São João da Boa Vista/SP, CEP: 13876-347 alinesquilasse@gmail.com
Intervenções assistidas por animais

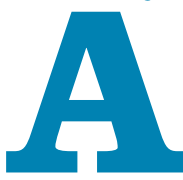

$s$ intervenções assistidas por animais (IAA) vêm sendo utilizadas ao redor do mundo, inclusive no Brasil. Chelini (2016a) refere que os estudos da área ainda são incipientes, mas que a academia já começa a se dedicar ao assunto. As IAA são divididas basicamente em três grandes grupos, postulados por Chelini (2016a):

A primeira abrange as intervenções terapêuticas conhecidas como terapias assistidas por animais (TAA). De acordo com a definição da organização Pet Partners ${ }^{(1)}$, a TAA consiste na utilização da relação humano-animal como parte integrante do processo terapêutico. As intervenções de TAA são organizadas e supervisionadas por um profissional da área da saúde que tem objetivos precisos e registra e avalia os resultados das intervenções. Diferencia-se nisso das atividades assistidas por animais (AAA), que têm por objetivo melhorar a qualidade de vida dos assistidos e que não requerem a supervisão de um profissional da saúde. Os resultados das AAA não são necessariamente avaliados. Intervenções assistidas de cunho pedagógico são agrupadas sob o nome de educação assistida por animais (EAA). 
Para construção deste artigo, foi constatada uma problemática enfrentada pela comunidade científica que é referente às pesquisas na área. Rodrigues (2016) relata que há uma série de deficiências nas pesquisas, principalmente as relacionadas aos critérios metodológicos. Este é um desafio para pesquisadores, pois os avanços na área ocorrerão quando as pesquisas passarem a adotar melhores critérios metodológicos.

Há inúmeras razões para a realização de estudos que envolvam as IAA. Rodrigues (2016) ressalta que elas podem ser um valioso adjuvante ao processo terapêutico, pois favorecem melhoras "cognitivas, físicas, sociais, emocionais e a qualidade de vida dos indivíduos".

Os primeiros estudos sobre os benefícios da TAA foram realizados com pacientes que apresentavam quadros clínicos psiquiátricos e foram publicados nos Estados Unidos na década de 1960 por Boris Levinson, Sam e Elizabeth Corson (FÜLBER, 2011).

Já no Brasil, nos anos 1950, Nise da Silveira, médica psiquiatra, psicanalista e terapeuta ocupacional do Centro Psiquiátrico Pedro II, localizado no Rio de Janeiro, introduziu a utilização de animais no tratamento de pacientes esquizofrênicos após a adoção de uma cadela por um dos doentes. Quando percebeu a incomplexidade de vínculo dos pacientes com os cães, Nise desenvolveu o conceito de "afeto catalizador", que se baseia na constância e no comportamento não invasivo de um coterapeuta não humano, confirmando que o animal reúne qualidades que o tornam um ponto de referência no mundo externo, o que favorece a retomada de contato do doente com a realidade (FÜLBER, 2011).

Outra pioneira em TAA, também no Brasil, é a doutora Hannelore Fuchs, médica-veterinária e psicóloga que coordena o programa Pet Smile, que tem o objetivo de desenvolver a autoconfiança e as habilidades motoras e de diminuir a ansiedade em crianças (SILVA, 2011).

\section{Escolha das espécies e critérios preliminares}

Chelini (2016b) destaca que, ao se falar em IAA, a maioria das pessoas faz a associação com as visitas de cães em hospitais ou instituições para idosos, ou com a equoterapia. Há bons motivos para isso, pois esses dois tipos de IAA constituem a maioria das ações terapêuticas, educacionais ou, simplesmente, de atividade assistidas. Além de cães e cavalos, outros animais, domésticos ou não, já foram testados nas IAA. A organização Pet Partners autoriza o registro de cães, gatos, porquinhos-da-índia, coelhos, ratos domesticados, cavalos, jumentos, lhamas, alpacas, algumas raças de porcos de estimação e aves como animais de terapia, mas não reconhece sua potencialidade para uso na terapia assistida.
Chagas et al. (2009) destacam que todos os animais que entram em contato com os humanos sem oferecer-lhes perigo, podem ser considerados animais de terapia, porém ressaltam que o cão é o principal, pois apresenta maior afeição pelas pessoas e cria respostas positivas ao toque.

O convívio com cães estabelece benefícios emocionais e eles podem ser classificados de acordo com o trabalho que desempenham, como cães de serviço, guias, de alerta, de regaste, para deficientes e farejadores. Os cães de serviço são comumente utilizados por deficientes que tenham qualquer tipo de limitação física e assumem uma série de tarefas, como empurrar a cadeira de rodas ou ajudar no equilíbrio (FÜLBER, 2011).

O termo "coterapeuta" foi proposto por Nise da Silveira e hoje é muito utilizado para os animais envolvidos com IAA. A referida pesquisadora tinha preferência pelos gatos e reconhecia que nem todos se identificavam com a liberdade que os felinos exigiam para viver bem e com o seu caráter independente, que os diferia dos cães (CHELINI, 2016b).

Para que um animal participe de atividades de IAA, é indispensável que ele seja submetido a alguns procedimentos: ser escovado diariamente desde filhote, ser banhado e ter as unhas aparadas. A característica imprescindível que qualquer animal de IAA deve apresentar é a de ser sociável, tanto com outros animais como com seres humanos. Ele deve gostar da companhia de pessoas, ainda que desconhecidas e em grande número, aceitar o colo ou ser pego nos braços; deve tolerar luzes, cheiros fortes e sons repentinos e altos, mantendo-se calmo, sem apresentar comportamentos de fuga ou de agressividade. A Pet Partners estabelece que o animal deve ter pelo menos um ano de idade e não pode ter histórico de agressão. Grande parte dos gatos não apresenta o perfil apropriado para participar de IAA, porém, com treinamento orientado por profissional qualificado, os mais predispostos podem tornar-se coterapeutas confiáveis (CHELINI, 2016b).

Fülber (2011) afirma ainda que, para atuar como coterapeuta, os animais devem usar coleira, ser supervisionados o tempo todo, ser transportados em caixas e colocados em contato com o paciente sobre uma toalha, para evitar arranhões.

Outros animais que também participam das IAA são os ratos, porquinhos-da-índia e coelhos, e a vantagem desses animais é o seu tamanho reduzido, que permite a sua atuação em ambientes considerados muito pequenos para os cães. Evidentemente, eles devem seguir as mesmas características citadas anteriormente. Vale lembrar que esses animais não possuem uma longa história de relação amistosa com o ser humano, ao contrário de cães, cavalos e gatos. $\mathrm{O}$ fato de serem manipulados por pessoas 
desconhecidas pode gerar uma situação de estresse para a maioria dos animais, desencadeando comportamentos de medo e de agressividade. Destaque-se ainda que, por serem suscetíveis a infecção por agentes etiológicos de zoonoses, suas condições de saúde deverão ser sempre atestadas por um veterinário especializado e com experiência clínica com roedores e lagomorfos. Além de coterapeutas, eles também são utilizados como "coeducadores", pois como os porquinhos-da-índia têm uma aparência atraente e são tranquilos e diurnos, eles estão ativos no momento em que alunos estão nas atividades escolares, conforme exemplo de Chelini (2016): "Porquinhos-da-índia hospedados aos pares nas classes de diversas escolas de ensino fundamental na Austrália parecem ter sido capazes de estimular as habilidades sociais dos 127 alunos envolvidos no programa e de melhorar o seu comportamento".

Outros animais que são muito utilizados em IAA são os de produção, como vacas, cabras, galinhas, jumentos entre outros. Essa modalidade é bastante representada no Brasil na área de educação, em sítios e fazendas, que recebem alunos por períodos curtos, com o objetivo de proporcionar o contato com a natureza, conhecimentos sobre os animais e noções de ecologia em um ambiente seguro e controlado. No Brasil, ainda não foi realizada qualquer tipo de intervenção assistida por esses tipos de animais, mas na América do Norte, na Austrália e na Europa, eles já têm sido utilizados. Na Europa existe um programa conhecido como Green Care, em que os fazendeiros disponibilizam suas propriedades para o desenvolvimento dessas atividades com intuitos terapêuticos. Os países com maior número de fazendas Green Care são Noruega (550), Holanda (430) e Itália (325) (CHELINI, 2016b).

Os répteis, como serpentes, iguanas e tartarugas; e os anfíbios, como rãs e sapos, já têm muita popularidade como animais de estimação e não faltam donos entusiasmados para torná-los coterapeutas. A grande implicação disso é a escassez de veterinários com conhecimento nas áreas de répteis e anfíbios para atestar sua saúde e orientar o manejo correto, pois muitos desses animais podem ser fontes de infecção para salmonelas, mesmo que assintomáticos. De fato, nos Estados Unidos da América, há anualmente o registro de cerca de 50.000 casos de salmonelose associados a répteis (CHELINI, 2016b).

Fülber (2011) relatou que os golfinhos também podem ser utilizados em TAA, e que essa é uma área tida como mágica, denominada de delfinoterapia, em que os pacientes apresentam melhoria da capacidade motora, incremento da capacidade de comunicação, bem como aumento da independência, serenidade e cooperação. Os golfinhos são animais de enorme sensibilidade acústica, que possuem uma forma de comunicação semelhante ao sonar, apresentando grande capacidade de determinar a melhora neurofisiológica dos pacientes (SILVA, 2011).

O neurocientista John Lilly, em 1950, foi o primeiro a estudar a comunicação entre golfinhos e homens, e 20 anos mais tarde o seu trabalho mostrou as primeiras intervenções assistidas por golfinhos com crianças com distúrbios neurológicos.

Quanto à participação das aves em atividades de TAA, a literatura é pobre em publicações, mas convém lembrar que elas podem transmitir inúmeras infecções fúngicas ou bacterianas que provocam sérios problemas respiratórios ou gastroentéricos no ser humano (CHELINI, 2016b).

Os escargots também são animais não convencionais usados em IAA. Em Pirassununga, no heliciário da Faculdade de Medicina Veterinária da Universidade de São Paulo, eles são coeducadores no projeto Dr. Escargot, desenvolvido no ano 2000 por Maria de Fátima Martins, que tem o objetivo de ajudar na socialização de alunos da rede pública da região. O escargot pode ser levado facilmente à escola, é pequeno, limpo, barato e silencioso, e pode ser introduzido facilmente às atividades (CHELINI, 2016b).

Os cavalos são símbolo de força e altivez, tendo contribuído com o homem de forma exemplar nos últimos milênios. A equoterapia considera que com os movimentos do animal, os músculos do corpo do indivíduo que o está montando são estimulados, e há uma melhora da sua coordenação motora e equilíbrio. É um método terapêutico de reabilitação com validação científica, que traz benefícios motores, emocionais, cognitivos e sociais, proporcionando assim, uma melhor qualidade de vida. O cavalo, além de ser um instrumento de trabalho, também é um agente que motiva o praticante, uma vez que a terapia é realizada em ambientes externos que propiciam a sua socialização (VIEIRA, 2013).

A asinoterapia é muito semelhante à equoterapia, porém o animal utilizado é o burro, e faz o indivíduo ultrapassar, na medida do possível, danos sensoriais, motores, cognitivos, afetivos e/ou comportamentais (SILVA, 2011).

Deve-se destacar que a introdução dos animais na terapia não é indicada quando os pacientes não os aceitam, podendo reagir de forma agressiva e denegrir a saúde do animal, ou em pacientes com problemas respiratórios e alérgicos, a exemplo da proteína presente na saliva do gato (VIEIRA, 2013).

Kobayashi et al. (2009) ressaltam que em estudo realizado sobre infecção hospitalar, foi constatado que o visitante humano transmitiu mais infecções aos pacientes do que os animais. 


\section{Metodologia}

Esta pesquisa é uma revisão bibliográfica da literatura nacional. Para sua construção e fundamentação foram utilizados livros sobre a temática em questão, pesquisa de artigos especializados em bases de dados, participações em um evento e em um curso da área.

Para assegurar a relevância dos artigos obtidos na pesquisa, foram definidos os seguintes descritores: "intervenções assistidas por animais"; "terapia assistida por animais"; "atividade assistida por animais"; "cinoterapia"; "pet terapia"; "interação homem-animal". Os artigos referentes a dados históricos sobre a TAA não tiveram limite de data. Para as pesquisas quantitativas e experimentais, qualitativas, estudos de caso, e revisão de literatura, foi definido o prazo de dez anos, devido à escassez de publicações científicas.

Critérios de inclusão e exclusão da literatura foram definidos:

- Inclusão: pesquisas que contribuíssem com dados históricos, científicos e relatos de experiência.

- Exclusão: foram excluídas as pesquisas que não se enquadraram no critério das datas e dentro dos resultados dos descritores.

Para seleção de cursos e eventos, foi definido que estes deveriam contribuir com dados atuais e de relevância para a pesquisa, a fim de ajudar a elucidar dúvidas e esclarecer conceitos, além de contribuir com relatos de experiências pessoais.

\section{Resultados}

A literatura sinaliza que as IAA, quando bem utilizadas, geram inúmeros benefícios aos assistidos e podem ser empregadas nos mais diversos cenários. Machado et al. (2008) referem que a TAA pode ser aplicada em áreas relacionadas aos desenvolvimentos psicomotor e sensorial, em distúrbios físicos, mentais e emocionais, em programas que melhoram a capacidade de socialização ou na recuperação da autoestima. Esses recursos podem ser direcionados a pessoas de diferentes idades, instituições penais, hospitais, escolas e clínicas de recuperação.

Com esse mesmo enfoque Pereira, Pereira e Ferreira (2007) citam que a TAA também pode ser inserida no pré-operatório de pacientes, com a realização de visitas com cães treinados, o que reduz o estresse que antecede a cirurgia e propicia um melhor pós-operatório, diminuindo a necessidade de medicação analgésica.

Dotti (2005) menciona que os resultados mais significativos da TAA, e que podem ser extrapolados para diversos públicos, são físicos, mentais, sociais e emocionais.

Volpi e Zadrozny (2012) referem que os animais podem ser utilizados de forma benéfica em terapia, servindo como uma conexão para retirar o paciente de seu mundo interno e trazê-lo de volta ao mundo que o cerca. Eles servem ainda para lhes tirar o foco da enfermidade, suavizando seu sofrimento e ensinando sobre a vida e a morte.

Porém, ressalvas devem ser feitas, uma vez que os estudos ainda são recentes e carecem de mais pesquisas com critérios mais rígidos. No tocante aos benefícios e os estudos, Savalli e Ades (2016) salientam:

O relacionamento com animais, em especial os cães, promete uma série de benefícios, alguns deles já bem pesquisados; outros que ainda aguardam confirmações científicas. Os benefícios verificados são vários: proporciona o aumento de exercícios físicos e, consequentemente, a melhora do estado geral da saúde cardiovascular; promove a interação com outras pessoas; apresenta um efeito antiestresse; representa um suporte social e de afeto, entre outros.

Diante desse cenário, não restam dúvidas de que a utilização das IAA pode favorecer as interações entre ser humano e animal, tornando suas relações mais próximas e diminuindo as nuances antropocêntricas que circundam essas relações.

\section{Conclusão}

De acordo com a literatura consultada, foi constatado que as IAA podem ser um importante adjuvante para a saúde e o bem-estar dos seres humanos, podendo ser aplicadas nos mais diferentes contextos e com os mais distintos públicos.

Embora as evidências ainda não sejam numerosas, os resultados já obtidos são promissores e indicam a necessidade de novas investigações que adotem metodologias observacionais e experimentais, com um acompanhamento em longo prazo. Ademais, também se faz necessário um estudo sobre o bem-estar dos animais participantes, pois são raras as pesquisas relacionadas a esse tema.

$\mathrm{Na}$ aplicação das IAA, sejam elas quais forem, o médico-veterinário é de extrema importância, pois além de manter a saúde dos animais, ele deve estar sempre atento para a saúde pública. A preocupação mais nítida está no risco zoonótico em IAA, porém cabe a ele, ao tutor e a todos os envolvidos reduzirem esses riscos e, com isto, proporcionar melhores resultados aos assistidos. (*) 


\section{Referências}

CHAGAS, J. N. M. et al. Terapia ocupacional e a utilização da terapia assistida por animais (TAA) em crianças e adolescentes institucionalizados. Revista Crefito-6, Fortaleza, n. 14, 2009. Disponível em: <http://patastherapeutas.org/wp-content/ uploads/2015/07/TO-e-adolescentes-institucionalizados.pdf $>$. Acesso em: 15 maio 2017.

CHELINI, M. O. M. Apresentação. In: CHELINI, M. O. M.; OTTA E. (Coords.). Terapia assistida por animais. Barueri: Manole, 2016a. p. XIII-XVIII.

Cães, cavalos... e os outros? In: CHELINI, M. O. M.; OTTA E. (Coords.). Terapia assistida por animais. Barueri: Manole, 2016b. p. 312-326.

DOTTI, J. Terapia e animais. São Paulo: PC, 2005. 294 p.

FÜLBER, S. Atividade e terapia assistida por animais. 2011. 27 f. Monografia (Graduação em Medicina Veterinária) - Faculdade de Veterinária, Universidade Federal do Rio Grande do Sul, Porto Alegre, 2011. Disponível em: <https://bit.ly/1MFvpPr>. Acesso em: 15 maio 2017

KOBAYASHI, C. T. et al. Desenvolvimento e implantação de terapia assistida por animais em hospital universitário. Revista Brasileira de Enfermagem, Brasília, v. 62, n. 4, p. 632-636, 2009. Disponível em: <https://bit.ly/2twHVOZ>. Acesso em: 15 maio 2017.

MACHADO, J. A. C. et al. Terapia assistida por animais (TAA). Revista Cientifica Eletrônica de Medicina Veterinária, Garça, v. 6, n 10, jan. 2008. Disponível em: <https://bit.ly/2K0OX9E>. Acesso em: 15 maio 2017.
PEREIRA, M. J. F.; PEREIRA, L.; FERREIRA, M. L. Os benefícios da terapia assistida por animais: uma revisão bibliográfica. Saúde Coletiva, São Paulo, v. 4, n 14, p. 62-66, maio 2007. Disponível em: <https://bit.ly/2tksCcO>. Acesso em: 15 maio 2017.

RODRIGUES, C. V. M. Pesquisa científica em terapia assistida por animais. In: CHELINI, M. O. M.; OTTA, E. (Coords.). Terapia assistida por animais. Barueri: Manole, 2016. p. 327-360.

SAVALLI, C.; ADES, C. Benefícios que o convívio com um animal de estimação pode promover para saúde e bem-estar do ser humano. In: CHELINI, M. O. M.; OTTA, E. (Coords.). Terapia assistida por animais. Barueri: Manole, 2016. p. 22-43.

SILVA, J. M. Terapia assistida por animais (revisão de literatura). 2011. 39 f. Monografia (Graduação em Medicina Veterinária) - Centro de Saúde e Tecnologia Rural, Universidade Federal de Campina Grande, Patos, 2011. Disponível em: <https://bit. ly/2KetuJC>. Acesso em: 15 maio 2017.

VIEIRA, F. R. A terapia assistida por animais (TAA) como recurso terapêutico na clínica da terapia ocupacional. 2013. 56 f. Monografia (Graduação em Terapia Ocupacional) - Faculdade de Ceilândia, Universidade de Brasília, Brasília, 2013. Disponível em: <https://bit.ly/2lglmDB>. Acesso em: 15 maio 2017.

VOLPI, D.; ZADROZNY, V. G. P. Benefícios da TAA: uma contribuição da psicologia. 2012. 32 f. Monografia (Graduação em Psicologia) - Centro de Ciências da Saúde, Universidade Regional de Blumenau, Blumenau, 2012. Disponível em: <https://bit.ly/2MWcAhi>. Acesso em: 15 maio 2017. 